\title{
The (in)Significance of the Addiction Debate
}

\author{
Anna E. Goldberg (1)
}

Received: 3 July 2019 / Accepted: 18 November 2019/Published online:12 December 2019

(C) The Author(s) 2019

\begin{abstract}
Substance addiction affects millions of individuals worldwide and yet there is no consensus regarding its conceptualisation. Recent neuroscientific developments fuel the view that addiction can be classified as a brain disease, whereas a different body of scholars disagrees by claiming that addictive behaviour is a choice. These two models, the Brain Disease Model and the Choice Model, seem to oppose each other directly. This article contends the belief that the two models in the addiction debate are polar opposites. It shows that it is not the large amount of addiction research in itself what sets the models apart, but rather their extrapolated conclusions. Moreover, some of the most fiercely debated aspects - for instance, whether or not addiction should be classified as a disease or disorder - are irrelevant for the conceptualisation of addiction. Instead, the real disagreement is shown to revolve around capacities. Discussing addiction-related capacities, especially regarding impaired control, rather than the assumed juxtaposition of the two models can be considered the true addiction debate. More insight into the extent to which the capacities of the addicted individual were affected would be highly useful in various other areas, especially legal responsibility.
\end{abstract}

A. E. Goldberg $(\bowtie)$

Department of Criminal Law and Criminology, Maastricht University, P.O. Box 616, 6200 MD Maastricht, the Netherlands

e-mail: anna.goldberg@maastrichtuniversity.nl
Keywords Neurolaw Addiction debate Brain disease model $\cdot$ Choice model $\cdot$ Capacities $\cdot$ Criminal responsibility

A large number of individuals worldwide struggle with substance addiction; over 20 million in the USA alone [1]. Despite such a large population, or perhaps because of it, addiction remains difficult to conceptualize and define. This is neither new nor controversial: it seems that, historically, there has not been a consistent explanation of the phenomenon [2]. Two main views currently dominate the so-called addiction debate: the Brain Disease Model (BDM) and the Choice Model (CM). According to the first, addiction should be framed as a compelling, disease-like condition [3]. The latter, however, asserts that addiction ought to be explained in terms of non-pathological mechanisms of choice and motivation [2]. As such, there seems to be little agreement on some fundamental aspects of the phenomenon. This affects not only scholars who study addiction directly, but also professionals in other branches concerned with addicted individuals, such as health care and criminal justice systems. For instance, without clarity on the nature of addiction, decisions on how to conceptualize addiction in the context of legal responsibility may become complicated and controversial. Therefore, it is necessary to look beyond the disagreements and address the common grounds in the addiction debate. This article aims to identify which aspects of the addiction debate are truly contentious, and which are not. Importantly, I highlight the aspects of the addiction 
debate that are directly relevant for determining the legal responsibility of addicts and their addiction-related crimes. However, the paper only intends to show how the addiction debate is (ir)relevant for our legal responsibility practices in a general way, without going into the juridical details on when and how addicted persons could be held criminally responsible for their actions. Exploring these legal issues, which may also differ from system to system, falls outside the scope of this article. ${ }^{1}$

The article starts by attempting to provide a neutral definition of addiction. By identifying undisputed and common elements that characterize addiction, and combining these to form a workable definition, this could be a great starting point for unbiased research and discussion. Next, I describe the two addiction models central to this paper: the BDM and the CM. Their fundamental arguments are explained, which leads to the observation that many characteristics of the models are not necessarily disputed by each other. Nonetheless, the next section discusses two elements that the models seem to disagree upon the most, namely, the chronic nature of addiction and the amount of control that addicts can exercise. The latter in particular leads to much controversy and disagreement and is reviewed extensively. The penultimate section elaborates on the true difference between the two addiction models, which arguably are not the direct research findings but rather their ensuing conclusions. It is suggested that parts of the addiction debate are neither necessary nor relevant in the conceptualisation of addiction, especially not when discussing criminal responsibility. Before reaching a conclusion, the final part of this paper argues that the most important aspects of addiction research, independent from certain models, are the capacities of the addicted individual, and that using concepts such as disorder, disease or brain disease is not necessarily informative in the addiction debate and may only derail the discussion from such capacity-based arguments.

\section{Starting Point: Agreeing on a Definition}

A first consequence of the controversy and disagreements surrounding (theories of) addiction is the lack of

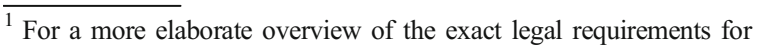
criminal responsibility in different jurisdictions, and the influence that addiction may have on this, please refer the forthcoming article by Goldberg and Roef, which discusses the basis for legal insanity from a capacitarian perspective (Goldberg \& Roef [4]).
}

consensus regarding a definition. Colloquially, the concept of addiction is well-understood. Still, such a definition lacks depth and specificity, as illustrated by the following: in the Oxford Dictionary, addiction is uninformatively defined as "the fact or condition of being addicted to a particular substance or activity" [5]), which requires the additional definition of "being addicted". This is then defined as being "physically and mentally dependent on a particular substance" [6]. Of course, one may continue to wonder what the meaning of dependence is, and so forth. As such, there is no true explanatory or discriminating value in the commonly understood meaning of addiction. However, scholarly definitions do not offer clarity either. The definition of addiction under the BDM is as follows: "Drug addiction is a brain disease that develops over time as a result of the initially voluntary behavior of using drugs. The consequence is virtually uncontrollable compulsive drug craving, seeking, and use that interferes with, if not destroys, an individual's functioning in the family and in society." ([7], p. 75). The descriptions employed under the CM is a marked contrast: "[addicted] individuals caught in a destructive pattern of behavior retain the capacity to improve their lot and that they will do so as a function of changes in their options and/or how they frame their choices." ([8], p. 4). At first glance, one can already see how the gravity of the first definition ("virtually uncontrollable" and "destroys") seems to oppose the lighter, more optimistic outlook ("retain the capacity to improve") stated by proponents of the CM. Clearly, favouring one definition over the other will result in a bias before even starting to study the matter in more detail. Research that departs from the first definition will naturally operate on a brain-based methodology and hence find brain-related evidence. Research within the CM is more likely to address sociopsychological factors in their research. As such, it is necessary to acknowledge a more neutral definition of addiction to avoid confirmation bias.

Developing a neutral definition immediately raises concerns: how can such diverging views be represented by one definition? In an attempt to overcome this matter, Sussman and Sussman have conducted a thorough literature review incorporating different theoretical perspectives. By identifying common elements in all definitions, they identified the most common and pertinent points posited by the different addiction scholars [9]. All these elements combined form a definition that captures the essence of the condition, whilst simultaneously representing different viewpoints in the addiction 
debate. Using their research as a starting point, the following definition could be an impartial starting point for a discussion on addiction: addiction is a consequential mental state of the use of a substance, characterized by a preoccupation with the substance-using behaviour that is only satiated temporarily after using the substance, where the individual concerned experiences varying degrees of difficulty controlling this addictive behaviour despite its harmful consequences. This definition, adapted from Sussman and Sussman [9], respects both the $\mathrm{CM}$ and the BDM, as well as acknowledges the heterogeneity of addicted individuals. Moreover, it recognizes different elements that are characteristic of the phenomenon: the preoccupation with the substance, the urges and the harmful consequences, thereby addressing the gravity of the condition but allowing for individual differences therein. As such, it seems possible to agree on a definition that does not automatically result in conflict between the two models. However, when addressing the foundations and core assumptions of the two models, the debate seems unavoidable.

\section{Opposing Models}

The central idea of the BDM is that addiction is a chronic, relapsing brain disease $[3,10]$. It is characterized by three aspects: compulsively seeking and taking drugs, losing control with respect to limiting intake, and negative emotional states when access to substances is restricted [11]. Moreover, the BDM also often addresses genetics in relation to the inheritability of and susceptibility to addiction. Also referred to as the medical model, these theories are often accepted by medical and psychiatric bodies and professionals, such as the National Institute on Drug Abuse (NIDA) and the Diagnostic and Statistical Manual of Mental Disorders (DSM). The new DSM-5, for instance, refers to Substance Use Disorders and on its first page explains that "all drugs that are taken in excess have in common direct activation of the brain reward system, which is involved in the reinforcement of behaviors and the production of memories. They produce such an intense activation of the reward system that normal activities may be neglected" ([12], p. 482). This is the leading view in terms of governmental and health research institutes [13]. In fact, some popular publications on the BDM originate from the research conducted by Alan Leshner, the former director of NIDA, and his research is currently being expanded upon by NIDA's present-day director
Nora Volkow [14]. The wide range of the BDM's influence is illustrated by a simple Google search on the term addiction. The first ten hits are community platforms such as Wikipedia or centeronaddiction.org, but also government-funded informative websites like drugabuse.gov. These websites almost exclusively state, in their search hit description, that addiction is a brain disease. Clearly, the BDM has strong backing from governments and communities and it is the dominant perspective individuals encounter when searching for information on addiction. As such, the controversy of the addiction debate, or merely a more nuanced description of addiction beyond the BDM's version of it, seems to be limited to direct scholarly output.

Importantly, proponents of the BDM not only refer to the neurobiological effects drugs have on the brain but also project this onto various impairments as a result of these effects. Cognitive control, attention or motivational bias, and negative emotional states are seen as major complications resulting from said brain changes [15, 16]. As a result, the behaviour of addicted individuals is considered compromised and disordered in those aspects. Besides generalized neural consequences from repeated substance use that may explain why the addicted population can experience certain dysfunctions, the BDM also explains the role of individual differences in acquiring and maintaining addiction [10]. In other words, the model not only provides an explanation on a generalized level but also seeks to explain why some individuals will become addicted fairly quickly (and experience particular hardship in their attempts to cease) whereas other individuals may use drugs recreationally without experiencing dependence. Proponents of the BDM believe that the interaction between environmental factors and a genetic vulnerability may provide an explanation for this discrepancy [10].

Lastly, the chronicity of addiction is a final factor worth mentioning within the BDM. In fact, the BDM definition of addiction calls it a chronic, relapsing brain disease, thereby centralising this aspect. This implies that once the individual becomes addicted, he or she will remain vulnerable to relapse for the rest of his or her life. This view of addiction as a chronic relapsing condition is substantiated in two ways. First, there is a large body of evidence suggesting that the functional and structural changes in the brain are long-lasting and persistent, even after discontinuation of substance use [17-19]. If the disruption of the neural pathways persists throughout abstinence, then all the proposed deficits associated with 
addiction (i.e. lack of cognitive control, attention bias, negative affect) will continue to be present, resulting in continuous (chronic, if you will) vulnerability for relapse. Secondly, chronicity is also often implied through epidemiological indicators that suggest low recovery rates. For instance, prevalence studies in clinical and community settings suggest that around $60 \%$ of addicted individuals eventually achieve sustained recovery, after at least one (but more likely several) treatment episodes [20]. This suggests that the other $40 \%$ will continue to engage in a chronic cycle of use, withdrawal, abstinence, and relapse. Other studies that examined abstinence after treatment suggest even higher rates of relapse, for instance of $60 \%$ and even $90 \%$ [21, 22].

The biological and neuroscientific-based BDM stands in stark contrast to the CM view that takes individual autonomy and choice as a starting point. Most notably, Heyman provides extensive evidence that addiction is first and foremost in the hands of the addicts who choose to use or to abstain by their own account [2]. It is therefore not a chronic, relapsing brain disease but rather a matter of choice. The meaning of 'choice' in this model is somewhat ambiguous, as this is never defined in Heyman's book [2, 23-25]. When consulting other authors such as Baumeister, choice is related to agency: "the capacity to initiate and control action" ([26], p. 68). Moreover, in order to choose, there must be a capacity to make an informed choice: decisionmaking capacity [27]. This concept is often used when determining if an individual can consent, for instance to treatment. It is, therefore, not a stable capacity, generally considered present or absent, but rather specific to a particular time and context. In order to be considered capable to make and be responsible for one's decisions, decision-making capacity comprises at least four elements. ${ }^{2}$ The individual needs to be able to understand the facts, in order to make a well-informed decision; there must also be an element of appreciation of the nature and significance of that decision; the individual must have an ability to reason about this information; and the subject must be (physically) able to convey his or her choice (Berg, Grisso, \& Appelbaum [29]). The protagonists of the CM predominantly use epidemiological studies and first-person experiences to substantiate the claim that addiction is a choice. Accordingly, they

\footnotetext{
${ }^{2}$ Some authors add a fifth element to decision-making capacity, which requires a consistent and stable set of values (e.g. [27]; Buchanan \& Brock [28]).
}

relate the concept of choice to the voluntary nature of the addict's conduct to show that addiction is neither involuntary nor uncontrollable. The CM argues that the addictive behaviour is voluntary by looking at remission rates as well as explanations for and correlations with remission, both explained in turn.

In terms of epidemiological studies, it is widely known that relapse rates after treatment are high. However, according to the choice theory, this does not automatically imply that addiction is chronic and that most people fail to discontinue their drug use. Most of the studies that show such high relapse rates are focussed on a clinical population: addicts who were enrolled in treatment. However, addicts in treatment only represent a very small proportion of all people that suffer from addiction. For instance, a survey shows that only $10.9 \%$ of individuals who needed specialised treatment (hospital, rehabilitation or mental health facilities) actually received it [30]. These patients who do receive such treatment are often patients with severe pathology due to comorbid physical or mental conditions. Hence, they may have more severe pathology and problems than other addicts, thereby portraying an unrepresentative subgroup of all addicts [24]. Nonetheless, these speciality treatments are often offered in the treatment programs and institutes that participate in addiction prevalence studies. As a result, the astonishing relapse rates in epidemiological studies likely only apply to this clinical subgroup. In fact, it could very well be that the chronicity of this subgroup is mostly due to their comorbidities rather than a direct consequence of addiction, or due to the interaction between the two conditions. As such, saying that all substance dependencies are chronic because clinical patients often relapse is likely to be an overstatement. These numbers suggest that the conclusion about chronicity is more accurate when stating that at most, only this small clinical subgroup of addicts suffers from a chronic disease.

However, studies with a non-clinical population are difficult to conduct: if there is no registration of the addiction, how can they be studied and followed-up? To combat this issue, large sample studies address the prevalence and remission of addiction in the general population [31,32]. It is particularly interesting to assess the difference between lifetime prevalence rate and 12month prevalence rate. If addiction were a chronic disorder, then lifetime prevalence would not be very distinct from 12-month prevalence rates. Likewise, if truly chronic, addiction would have no different a remission rate than other mental disorders, which are less 
controversially considered to be chronic, such as schizophrenia. This particular study assessed addiction (as defined as Substance Use Disorder in the then-used DSM-IV) alongside several other mental illnesses such as anxiety and mood disorders, based on interviews with 900 participants. The results show that, in terms of prevalence rates, almost $15 \%$ of the participants met the criteria for addiction at some point in their lives, whereas only $3.8 \%$ could be considered addicted in the past year. These results were in concordance with similar epidemiological studies. A more detailed overview of these findings shows that all such studies report recovery rates between 60 and $80 \%$, suggesting that the large majority of addicts do not experience addiction chronically. Secondly, this information was combined with the results that by age 25 , already half the population who had ever met the criteria for addiction did not report any symptoms anymore. Further, by age 37, approximately $75 \%$ no longer reported symptoms of addiction. It is consequently suggested that most addicts cease their drug use by the time they reach their thirties or forties [33]. They seem to 'mature out' or 'age out' of their conditions. These recovery rates deviate and stand out from the trends that other chronic disorders show, such as schizophrenia.

Besides the conclusions from epidemiological studies, the CM largely focusses on explanations associated with these high recovery rates, particularly in non-clinical samples [34]. Findings from one study indicate a positive correlation between marriage and recovery rates, meaning that those who are (getting) married are more likely to be able to quit using drugs. Having a close circle of family members has also been shown to play a big role in remission rates, as do economic or judicial pressures and hardship, and respect from relatives $[8,35]$. This is often interpreted as indicative of practical or moral concerns for not wanting to continue drug use: they are correlates of choice. These ideas are also supported by more personalized accounts on what it is like to use drugs, to be addicted and also to quit [23]. Interestingly, even someone who seemed to have a very difficult time resisting drugs gave very straightforward accounts for finally abstaining from substances. ${ }^{3}$ Such stories seem to revolve around a sudden

\footnotetext{
${ }^{3}$ For instance, Harry is described as a highly addicted individual who ruins his successful career as a lawyer and divorces his wife due to his cocaine addiction. Nonetheless, these events were not enough to stop Harry from using. What made him stop? He states that he woke up one day and realized that he could not continue like this. That day, he stopped using drugs. See also: [23], p.58-59.
}

change of mind or a noteworthy occurrence that provided insight into the destructive behaviour, for instance, a car accident or the sudden loss of income. What they all have in common is that they describe and explain their reasons for quitting as part of a conscious, voluntary choice. Needless to say, these stories are only a fraction of the different paths that may lead to abstinence or continuation of drug use. However, it is compelling that treatment is not essential to recovery for a subgroup of addicts and that reasons for quitting may be very unambiguous.

Centralising these two models, emphasising voluntary choice versus involuntary biology, is interesting in itself. They seem to focus mostly on one perspective of addiction in their attempts to explain the phenomenon. However, it appears that these factors are not necessarily mutually exclusive and that multiple causes of addiction exist and interact, rendering it an intrinsically heterogeneous phenomenon. Both models are crucially different in their explanation of the most central element in addiction. Of course, that does not mean that the models deny the existence of other influential factors: Leshner clearly states that "addiction is not just a brain disease" ([3], p.46, emphasis added) and Heyman acknowledges the inheritability of addiction ([8], p.4). However, the authors conclude that those characteristics are less crucial to the conceptualisation of addiction than others. It is exactly this discussion, determining which elements are most relevant and which factors should be prioritised when addressing an addict's behaviour (i.e. their choices or their brains), which is central to the addiction debate. For that reason, it is worthwhile to explore the exact disagreements between the two models further.

\section{The Apparent Debate}

The BDM and the CM seem to disagree the most on two aspects: the chronicity of the condition and the amount of self-control, discussed in turn. In terms of chronicity, the $\mathrm{CM}$ outlines the results from epidemiological studies on prevalence, indicating that apart from a clinical minority, most addicts do recover. Conversely, the BDM seems to focus largely on the high relapse rates and the brain science that shows disrupted neural pathways, which seem to persist even after abstinence is achieved. A likely explanation for this difference is that addiction can be categorized based on severity, resulting in different addiction categories showing different characteristics. Those who are severely addicted and are often 
simultaneously experiencing comorbid psychiatric disorders may be categorized as the clinical subgroup, predominantly addressed by the BDM. By contrast, the CM seems to deal with a subgroup that has a less severe (comorbid) pathology $[36,37]$. As a result, the debate between the BDM and the CM with regard to chronicity seems to have a relatively 'easy' answer, as they are likely referring to two different subgroups of the same condition.

A greater point of difficulty is thus the large difference in the models' perception of the amount of self-control that addicts can or cannot exercise. Throughout the discussion on addiction, particularly in terms of the BDM, scholars refer to an inability to control oneself, implying that addictive behaviour is involuntary. But what exactly is meant with compulsion, (in)voluntary behaviour, or self-control? When arguing that addicts are capable of freely choosing their behavioural actions, CM proponents seem to refer to a capacity to understand, appreciate and reason with the circumstances: a cognition-centred decision-making capacity, as referred to earlier. When the BDM advocates mention voluntary choice or, rather, the lack thereof, they suggest a more literal interpretation, namely the incapacity to do otherwise, or lack alternative possibilities, supposedly through the existence of strong (even irresistible) urges: a matter related to the volitional capacity for control. As such, what is meant with these terms seems to be the main source of disagreement between the two addiction models.

Interestingly, the BDM uses a 'lack of control' as a substantial argument for their interpretation of addiction as a brain disease, often without clearly stating what that lack entails. For instance, Leshner claims that once the individual becomes addicted (which starts as a voluntary endeavour), the associated brain changes result in craving, seeking and using drugs in a manner that is no longer under such voluntary control ([3], p. 47). Charland additionally claims that the use of drugs influences decision-making to the extent that these "physiological and psychological compulsions usually [...] nullify any semblance of voluntary choice" ([38], p. 41). However, many much-read and cited articles on the BDM do not specify what is meant by 'not under control' or 'voluntary choice'. At a minimum, they ought to refer to a diminished ability to control one's behaviour and decision-making [39]. At a maximum, they should state that there is no choice in the literal sense: for the addict, there are no alternative possibilities or options available but the use of drugs.
It is important to note that this choice of words, 'uncontrollable' and 'involuntary', can already lead to much confusion, if we mistakenly associate these terms with the metaphysical conditions of free will, i.e., the ability to do otherwise (alternative possibilities) and being the ultimate source or uncaused cause of one's decisions. However, the general philosophical question whether or not anyone had the capacity to do otherwise in any event, or has ultimate causal control (beyond any external or internal factors), and not just when using drugs, should not be confused with the more practical and empirical perspective on voluntariness that is (and ought to be) central in the addiction debate. ${ }^{4}$ In other words, there is a risk of two overlapping discussions: how much control the addicted person has over his or her behaviour and therefore to what extent he or she is responsible, but also whether humans have contracausal free will at all. This latter philosophical issue of free will and causal determinism is not something that will easily change in light of neuroscientific evidence: it is a centuries-old question reserved for philosophers to attempt to answer [41]. Hence, the BDM may generate exciting new data regarding addiction and the brain, but the problem of how much actual control the addict truly has requires a more practical assessment of capacities and not a philosophical discussion on free will. When scholars of the BDM examine these empirical matters relating to choice and control, for instance, impulsivity and inhibition, it would increase clarity if they minimize terms suggesting a philosophical (libertarian) notion of free will, such as complete involuntariness. Discussing 'empirical' voluntariness in the sense of the concrete capacity to restrain or control oneself (in other words, to say no to drug use) is much more relevant to the addiction debate, even when one would metaphysically argue that having this capacity or not is fully determined by antecedent (brain) events and states. This also seems to be the level in which the CM discusses choice and decision-making: that is, on a practical, capacity-based level rather than a philosophical all-or-nothing dispute.

\footnotetext{
${ }^{4}$ Arguably, if the metaphysical perspective of determinism or universal causation is true, it is not only true for people suffering from a neurologically ingrained or determined addiction, but for everyone. Discussing addiction in light of the philosophical free will debate does not give us any valuable information that enables us to distinguish addicted people from non-addicted people with regard to questions of freedom and legal responsibility. For both categories, the philosophical challenge is the same. For a more in-depth discussion on this matter see also (Focquaert et al. [40], pp. 106-107).
} 
In short, when discussing control, there ought to be a sole focus on assessable qualities such as impulsivity, understood as the capacity to restrain and inhibit one's behaviour. By addressing such qualities, empirical studies have aimed to gain insight into the motives and processes underlying control and choice [42]. There is a clear association between addiction and impulsivity, suggesting that addicts have less control over their choices than non-addicted individuals. If both models would discuss addiction in terms of measurable qualities, such as impulsivity, the discussion on addiction would benefit tremendously, as the parameters of the discussion would be equal (as opposed to the different interpretations of 'choice' and 'control' as the two models currently employ).

Importantly, the translation of impulsivity (as an assessable representation of control or lack thereof) to determining exactly how much control there was at a certain point in time remains vague and speculative at best. This is a fundamental problem with the debate on addiction and controlled behaviour as outlined eloquently by Morse in 1985: "If or to what degree a person's desire or impulse to act was controllable is not determinable: there is no scientific test to judge whether an impulse was irresistible or simply not resisted." ([43], p. 817). Although Morse considers this impossible to determine, empirical results can be useful in at least providing evidence on practical questions of control, and at most determining it altogether [44]. ${ }^{5}$

\footnotetext{
${ }^{5}$ At this point it is important to stress why and how empirical voluntariness, such as impulsivity, escapes the free will debate. In order to be free in a traditional metaphysical sense two main conditions are required: alternative possibilities and being the ultimate source or uncaused cause of the decision. Both are philosophically challenged by the idea of causal determinism. Philosophical discussions on whether we have real contra-causal free will, or whether free will, responsibility and determinism are compatible, transcend the addiction debate. For instance, if there is no free will, then this is true for everyone, not just for addicts. Also, if one would hold the position that free will and responsibility is compatible or incompatible with determinism, then again this view is independent from addiction (or any other disorder). Therefore, as mentioned in footnote 3 , being addicted does not make a difference to this philosophical challenge: if causal determinism is true, we do not have any alternative possibilities in any event, neither are we the uncaused cause of our choices, whether we are addicted or not. As the words 'choice' and 'uncontrollable' may both suggest the existence or lack of alternative possibilities, by focussing on impulsivity, we circumvent this metaphysical question and discuss the effects of addiction on capacity on a practical and empirical level. After all, the specifics of addiction (and the debate) would not be relevant to be discussed on an overarching, metaphysical level as the challenge is the same for all behaviour, not just addiction (see also [40, 45]).
}

The BDM model can help explain why addictive behaviour is more difficult to control in theory. The ability to inhibit behaviour requires cognitive resources and skills, which may be limited or impaired in addicts. It is argued that to a certain extent, addicts may very well be able to control themselves or respond to reasons, but this ability can be depleted at times, particularly as a result of cravings. Consequently, control may be lost. The analogy of somebody hanging onto a cliff is often used, indicating that the individual can only hang on for so long before their strength is completely depleted and she has to let go [37]. Hence, the BDM holds the view that self-control is impaired, which is a reasonable conclusion. However, BDM scholars also tend to state that drug cravings can result in involuntary actions, which is a poor choice of words due to the aforementioned free will connotation.

The CM raises some important questions regarding the meaning of uncontrollable, compulsive and involuntary behaviour. Although not disagreeing on the neural processes that are the basis of said behaviour, it is considered a problem that addiction seems to be equated with a lack of control without explaining what that means [25]. On what basis is addiction considered to consist of fully uncontrollable actions? Heyman suspects that the assumption of involuntariness of addiction that the BDM explains is inferred from the fact that addictive behaviour is self-destructive. If one knows that by using substances they will lose their job, then the only reasonable explanation of why they still keep using is that they must somehow be compelled to do so. However, such an argument makes the crucial assumption that self-destructive behaviour is by definition involuntary. This is something Heyman contests by arguing that many types of behaviour are self-destructive yet deliberately, at least voluntarily, pursued [2]. Similarly, Hanna Pickard argues against addictive behaviour as a compulsion [46]. She outlines that neuroscientific evidence merely explains why addictive substances may be difficult to resist, especially compared to other urges, but not why they are impossible to resist. In addition, she also refers to the possibility addicts have to avoid cues or drug-related stimuli. Easier said than done, she admits, but a highly successful treatment strategy (and something every alcoholic knows) is that to not relapse into drinking, one should not visit a pub.

To summarize, the wording of the definition used under the BDM seems to suggest that drug cravings are impossible to control, whereas several choice 
theorists claim that addicts are able to do as they wish. The argument that addicts are not compelled because there are always alternative possibilities (together with a capacity to control), neglects an experiential and individualist account of addiction. Qualitative reports of addicts' experiences indicate that many users have experienced moments of intense urges and cravings, often described as uncontrollable, notwithstanding that, in general, addicts are in control of their actions and decisions [2]. Moreover, a lack of control also manifests itself in other forms and shapes, such as the automatism of lighting a cigarette before being well-aware of the movement, or a sudden craving relapse after sustained periods of abstinence. As a result, compulsion may be more than the simple dichotomy of it being present versus absent [47]. This view is also endorsed by Kennett and colleagues, who state that drug use may be an involuntary choice, but only after their self-control resources are exhausted. Is the behaviour therefore compelled? Not in the literal, metaphysical sense meaning predetermined or necessitated, but definitely in an experiential sense of being subjected to a very strong compulsion that may feel impossible to resist [37].

Lastly, an important aspect of control in addiction is diachronic control: rational and controlled behaviour in anticipation of moments where no such control is possible. That means that either the individual minimises the chances of such an 'uncontrolled' moment happening in the first place, or that he or she directly takes action against the feelings of diminished control [37]. To use examples related to addiction, the first scenario would be to avoid places that incite the temptation to use, for instance taking a different route home in order not to pass by a bar. An example of the second scenario would be to take medication or enrol in psychological treatment, which reduces cravings for the drug in general. In these moments, our executive functioning is not overwhelmed by temptation and enables the individual to think more clearly, contrary to the urges during cravings. This is also underlined by Morse, who states that addicts have "lucid, rational intervals between episodes of use", even if we would consider addicts irrational or coerced ([48], p. 191). Diachronic control can also be limited due to either internal or external barriers, such as an incapacity to foresee future consequences (myopia for the future) or a lack of treatment options or the ineffectiveness thereof [49]. Many internal barriers can be a result of diminished executive functions, which is largely controlled by the prefrontal cortex; the region that is most notably affected by addiction $[15,19,50]$.

\section{The Real Conflict}

Based on the previous paragraphs, this article advances two claims. The first claim is that despite the two addiction theories' voiced disagreements and impugning publication titles, ${ }^{6}$ the two models do not seem to disagree on the research per se. After all, some research findings are so robust that it would seem foolish to deny them outright. For example, the role of the environment (e.g. relatives or other social contacts) is crucial in acquiring, sustaining or ceasing substance use [51]. This feature is certainly a strong explanatory component in the $\mathrm{CM}$, but nonetheless also features in the BDM. "First, sustained exposure to drugs of abuse might be a prerequisite for drug addiction, but its emergence is ultimately a function of interactions between drug effects, biological and environmental factors, which are crucially influenced by the developmental stage of the individual." ([52], p. 559). Similarly, the CM does not negate the abundance of brain research on the long-lasting or even permanent effects that drug use has on the brain. For instance, Pickard states that "[...] there is no question that immoderate long-term drug use can affect neural mechanisms. Many drugs directly increase levels of synaptic dopamine, which may affect normal processes of associationist learning related to survival and the pursuit of rewards." ([46], p. 42). That does not mean, however, that the CM advocates support the inferential conclusion that these neurological changes leave the addict with no other choice than drug use, rendering addiction a disease of compulsion [46]. Similarly, the BDM does regard decision-making as crucially important in the development of addiction but contends that focussing on voluntary choice stigmatises patients and does not advance treatment [3]. As a result, the models are less far apart than they suggest: it is not the experimental data, but the conclusions derived therefrom where they differ most [53].

\footnotetext{
$\overline{{ }^{6} \text { Several books }}$ or articles were provocatively named after previously published well-known entries, such as 'Addiction is not a brain disease, and it matters' by Levy as a reply to Leshner's well-known 'Addiction is a brain disease, and it matters'.
} 
Both models dispute the opposing types of conclusions. To start with, the proponents of the CM highlight the fact that everything we do changes the brain: does that make our brain continuously disordered? That would be absurd since the brain is continuously changing, adapting and learning. The role of the everchanging brain in all situations highlights the need for a broader dimension of addiction than solely focussing on neurology. Consider, for instance, that the mere effects of dopamine do not distinguish between addictive drugs and other rewarding substances or activities, which also release dopamine but are not (as) addictive. This indicates that dopamine is a crucial component in the process, but also that dopamine alone is unable to explain addictive patterns. Another example is a statement by Leshner, saying "that addiction is tied to changes in brain structure and function is what makes it, fundamentally, a brain disease" ([3], p. 46). Try changing the word 'addiction' with any other activity that changes the brain, such as education, and the statement suddenly seems absurd. As such, the step from explanatory brain science to the conclusion that addiction is a brain disease can be considered one bridge too far.

On the contrary, the conclusion by some of the choice theorists that addiction is voluntary in the sense of 'under control' is also disputed due to their overgeneralised findings and statements. These broad conclusions are consequently applied to individuals who, as discussed, endure a very heterogeneous condition. For instance, consider the fact that most addicts mature out of their addiction by their late twenties and thirties. That still leaves a subgroup of (often severely) addicted individuals for whom addiction may very well be chronic. These addicts often suffer from severe comorbidities, such as mood, anxiety, or personality disorders [46]. As a result, these generalised findings by the CM may not apply to severely addicted individuals in terms of chronicity. Moreover, this subgroup may also experience their loss of control more severely, since they do not manage to age out of their use. For instance, descriptive studies illustrate cases of severely addicted individuals who continued using drugs despite the awareness that it may result in their death $[54,55]$. Such "hard" cases of addiction may indicate some people experience severely compromised decision-making. Hence, it sometimes seems as if both models are discussing a different phenomenon.

As briefly touched upon earlier, it is not inconceivable that the BDM and the CM are essentially referring to distinctly different 'types' of addicts. This is the second claim resulting from the previously discussed arguments. Whereas the previous claim suggests that, on a theoretical level, the two models tend to be more similar than they appear at first sight, this second claim relates to the most appropriate conceptualisation of addiction on an individual level. For some addicts, the view of addiction as proposed by the CM may accurately describe their situation and their concurrent responsibility, whereas, for others, the view as proposed by the BDM may be more appropriate. Not unlike the theories by Moffit on the development of antisocial behaviour [56], perhaps a taxonomy of addiction to highlight different pathways is appropriate. Such a taxonomy may distinguish between those who indeed are able to choose differently when the incentives are high enough and are likely to 'age out', and those who have very little capacity to restrain their choice to continue using drugs and are likely to suffer chronically. No such generally accepted taxonomy yet exists, apart from Marlatt's wellknown theory regarding relapse [57]. Evidently, a classification concerning the capacities of addicts, such as impulsivity, may be highly useful in certain fields dealing with addicts. Criminal justice systems, for example, may benefit from such a distinction, which may aid the correct legal approach of addicted offenders.

In sum, since the conclusions on the classification of addiction seems to be the fundamental matter in conflict, rather than the empirically studiable characteristics of addiction, it is not only difficult but also irrelevant to choose one model over the other objectively. For an understanding of addiction, it is much more important to find common grounds and to recognise that for some individuals the BDM may be more fitting. For others, there may be more overlap with the CM. The focus on the exact capacities of the individual, especially the capacity for control, is much more informative. After all, let us not forget that addiction is a condition that affects thousands, if not millions, of individuals worldwide. To strive for a universal model and application of it, therefore, does not do justice to the heterogeneity of the individuals involved.

\section{Disease, Disorder or Impaired Capacities?}

A final point worth stressing is a seemingly simple yet controversial issue regarding terminology. Besides actual differences in opinion regarding addiction, the 
terms used to refer to addiction cause further confusion and disagreement. Some titles of previously cited books, chapters and articles are "addiction is a brain disease"; "addiction: a disorder of choice"; "why addiction is not a disease"; "substance-related and addictive disorders", and so forth $[2,7,12,58]$. Nevertheless, none of them explicitly defines what is meant by disease or disorder, let alone the differences between them. Yet there is a heated discussion on whether or not addiction is a disease or disorder. For example, Heyman not only states that addiction is "by definition a disorder", but also that it is "disease-like". Confusingly, he also proposes a "non-disease account" of addiction, and all of this on the first page ([8], p. 1). A literature search reveals that the ambiguity of disease versus disorder is not only a problem in the addiction debate, but that there is generally little consensus when something classifies as a disease, disorder or neither. ${ }^{7}$

Disease is often used interchangeably with disorder, but is it truly synonymous? There are very little academic (i.e. scholarly) reviews regarding these concepts and their differences: in fact, I found none. One commentary even introduces the statement that disease is conceptually very different from a disorder but consequently does not explain what this conceptual difference is [63]. Specifically, on the topic of disorder, Jerome Wakefield concludes that this may be best described as a harmful dysfunction [64]. Harmful is consequently explained as a normative concept, based on social standards. Dysfunction, on the other hand, is a "scientific term" which is defined as a mental or physical malfunction or defect regarding the way in which it was originally designed to function evolutionarily. Consequently, there is no clear account of the difference between disease and

\footnotetext{
$\overline{7}$ On a historical note, the earliest found explanation of a disease stems from 1900 and states that there needs to be a disease cause (intrinsic, extrinsic or undetermined) and several pathological consequences ([59], p. 1703). Interestingly, this author gives the example of "nonparasitic matters introduced into the Economy" as a extrinsic disease cause. The disease that could stem from that? Alcoholism or plumbism (i.e. lead poisoning). It is not only interesting that alcoholism was used as a prime example of a disease, but also that it had an external cause, and that the economy was to blame. Others suggests that a disease is distinguished by levels of social or biological disadvantages, a statistical deviance, or the presence of a lesion [60]; that a disease ought to be conceptualized in a hybrid manner, by combining harm in everyday life with as a breakdown in a naturally selected system [61]; or that science never reflects objective medical explanations but that what we consider a disease is embedded in an ever-changing cultural and ethical framework [62].
}

disorder and one may wonder on what linguistic or conceptual basis scholars are so vigorously pleading against calling addiction a disease. Although not explicitly stated, it looks as if Heyman suggests that voluntariness is the reason that addiction is not a disease [8]. However, none of the aforementioned authors and the definitions they use discusses involuntariness as a criterion for disease: i.e. a disease does not have to be involuntary, and conversely, voluntary behaviour can still be a disease. The explanations of disease and disorder above seem to contradict his non-disease aetiology of addiction.

Additionally, individuals (including laypeople) often seem to associate the label "disease" with a lack of responsibility, suggesting that the mere existence of a condition can excuse someone's behaviour. Habitually equating disease with non-responsibility for behaviour could explain why one would be hesitant to label certain conditions as a disease. In such a case, a large body of individuals would automatically be exempted from a whole range of moral and legal responsibilities merely due to a diagnosis. However, this assumption that a disease results in (legal) non-accountability is wrong. Indicating the cause of certain behaviour does not negate responsibility. This is what Morse calls "the fundamental psycholegal error": mere causation does not excuse [65]. Knowing what causes certain behaviour (be it a mental disorder, a broken leg or external circumstances) is not informative about an individual's responsibility for said behaviour.

It seems that the last bottleneck for diseaseopponents is not so much the term disease as such, but rather the brain disease account [61]. Many scholars are classifying addiction as a disease and then automatically equating this with it being a brain disease. As discussed earlier, this conclusion is a statement disputed by many who feel that this neglects too many other important aspects of addiction. Therefore, referring to addiction as a disease, without specifying when or why a condition is called a disease, results in the automatic association with the BDM. Therefore, it seems best to use disorder and disease both interchangeably to indicate the disruptive nature of addiction without inferring what the cause is of addiction, by explicitly stating that disease does not automatically imply a brain disease. By doing so, the terminology is broad enough to satisfy all of those studying addiction. Perhaps it will lose specificity as such, but since addiction is a highly 
heterogeneous disorder that requires an individual approach to the cause and course of the disease, it may very well be left more general.

Finally, determining the cause of the addiction by labelling it a disease does not inform us on matters of responsibility. As elaborated upon earlier, rather than the label "disease" or "disorder", the relevant capacities ought to be discussed, such as the amount of rationality or more importantly, in the case of addiction, the amount of control $[66,67]$. For the law, these are also the widely agreed capacities that are required for responsibility: a diagnosis alone is hardly ever sufficient [68]. Those capacities inform us of whether the person can be considered responsible in various ways, as well as of the potential recidivism risk and possibilities for treatment. The labels "disease" and "disorder" do not. Hence, it could be that some reluctance in using the label disease stems from the erroneous assumption that disease in itself is sufficient to inform us on broader matters such as responsibility. Therefore, the discussion surrounding addiction is unnecessarily convoluted by quarrelling over labels, which derails the debate from what matters more: the capacities of the individual actor. Importantly, most legal systems do not differentiate between disease or disorder in their respective insanity or diminished capacity defences [68]. As a consequence, to determine responsibility, this terminology discussion is also irrelevant and conceptualizing addiction in terms of impaired capacities is much more informative.

Lastly, the insignificance of labels and models is also related to the fact that the presence of addiction per se (and the state of being addicted) is not a crime. People are only criminally responsible for harmful acts they commit, and not for their characters, their diseases and/or their disorders. Consequently, what matters for the law is limited to a practical question of which capacities the individual has, in which certain conditions such as addiction may influence these capacities. That means that the conceptualisation of addiction, and whether it is a brain disease or (ultimately) your choice is irrelevant in determining legal responsibility.

\section{Conclusion}

In this article, I have focussed on the concept of addiction in order to highlight and overcome some confusion and controversy regarding the addiction- debate. At the start, I attempted to provide a neutral definition of addiction that steers clear of normative conclusions and assumptions, which could be accepted by a majority of addiction researchers. Such a definition is recommended in order to research addiction from unbiased premises. Afterwards, it was shown that when highlighting the commonalities of the BDM and the CM, these models are not always as antithetical as they seem. To a large extent, the research and data on addiction are accepted by the majority of scholars. What is mostly contested is merely the extent to which the capacities of addicts are affected. This is a highly relevant matter, as, in fact, the capacities or a lack thereof is the only question that truly matters for determining legal responsibility. Moreover, this article has also explored many aspects of the addiction debate that divert attention from the central and the important discussion on capacities. By calling the behaviour of addicts involuntary, there is an immediate connotation of a lack of free will. Still, whether or not humans have free will is a different discussion entirely. This detracts from the discussion on what is likely meant by calling addiction involuntary, namely difficulty in controlling behaviour. Similarly, the discussion on whether addiction is a disease or a disorder is not relevant for understanding addiction, nor is it useful in determining responsibilities. Disease does not equate non-accountability and assuming certain consequences solely based on a diagnosis is a mistake. These disagreements regarding voluntariness and the disease label constitute a major part of the addiction debate, suggesting a large disagreement between the models. However, after careful analysis, the models merely seem to be in disagreement regarding the degree of affected capacity. Consequently, it is much more informative to attempt to reach a consensus regarding the capacities of the addict, most notably their ability for impulsivity and decision-making, rather than unnecessarily treating the two models as opposites.

Acknowledgements The author would like to thank Prof David Roef and Dr Katy de Kogel for their extensive and constructive feedback on the manuscript.

\section{Compliance with Ethical Standards}

Conflict of Interest The author declares that she has no conflict of interest. 
Open Access This article is licensed under a Creative Commons Attribution 4.0 International License, which permits use, sharing, adaptation, distribution and reproduction in any medium or format, as long as you give appropriate credit to the original author(s) and the source, provide a link to the Creative Commons licence, and indicate if changes were made. The images or other third party material in this article are included in the article's Creative Commons licence, unless indicated otherwise in a credit line to the material. If material is not included in the article's Creative Commons licence and your intended use is not permitted by statutory regulation or exceeds the permitted use, you will need to obtain permission directly from the copyright holder. To view a copy of this licence, visit http://creativecommons.org/licenses/by/4.0/.

\section{References}

1. Center for Behavioral Health Statistics and Quality. (2015). Behavioral health trends in the United States: Results from the 2014 National Survey on Drug Use and Health. Retrieved from https://ww w a m ha . gov/data/sites/default/files/NSDUH-FRR1-2014/NSDUHFRR1-2014.pdf

2. Heyman, G.M. 2009b. Addiction: A disorder of choice. Cambridge: Harvard University Press.

3. Leshner, A.I. 1997. Addiction is a brain disease, and it matters. Science 278 (5335): 45-47. https://doi.org/10.1126 /science.278.5335.45.

4. Goldberg, A. E. and D. Roef. (in press). Addiction, capacities and criminal responsibility: a comparative analysis. In A. M. Walterman, D. Roef, J. Hage \& M. Jelicic (eds.), Law, Science, and Rationality. The Hague: Eleven International Publishing.

5. Addiction [Def. 1]. n.d. In Lexico Online Dictionary, last retrieved October 23, 2019, from https://www.lexico. com/en/definition/addiction

6. Addicted [Def. 2]. n.d. In Lexico Online Dictionary, last retrieved October 23, 2019, from https://www.lexico. com/en/definition/addicted

7. Leshner, A.I. 2001. Addiction is a brain disease. Issues in Science and Technology 17 (3): 75-80.

8. Heyman, G.M. 2013. Addiction and choice: Theory and new data. Frontiers in Psychiatry 4: 31. https://doi.org/10.3389 /fpsyt.2013.00031.

9. Sussman, S., and A.N. Sussman. 2011. Considering the definition of addiction. International Journal of Environmental Research and Public Health 8: 4025-4038. https://doi.org/10.3390/ijerph8104025.

10. Volkow, N.D., G.F. Koob, and A.T. McLellan. 2016. Neurobiologic advances from the brain disease model of addiction. New England Journal of Medicine 374 (4): 363-371. https://doi.org/10.1056/nejmra1511480.

11. Koob, G.F., and N.D. Volkow. 2010. Neurocircuitry of addiction. Neuropsychopharmacology 35 (1): 217-238. https://doi.org/10.1038/npp.2009.110.

12. American Psychiatric Association. 2013. Substance-related and addictive disorders. In Diagnostic and statistical manual of mental disorders (5th ed., pp. 481-589). Washington, DC: Author. https://doi.org/10.1176/appi. books.9781585624836.jb16.

13. Vrecko, S. 2010. Birth of a brain disease: Science, the state and addiction neuropolitics. History of the Human Sciences 23 (4): 52-67. https://doi.org/10.1177/0952695110371598.

14. Courtwright, D.T. 2010. The NIDA brain disease paradigm: History, resistance and spinoffs. BioSocieties 5 (1): 137-147. https://doi.org/10.1057/biosoc.2009.3.

15. Goldstein, R.Z., and N.D. Volkow. 2011. Dysfunction of the prefrontal cortex in addiction: Neuroimaging findings and clinical implications. Nature Reviews Neuroscience 12 (11): 652-669. https://doi.org/10.1038/nrn3119.

16. Volkow, N.D., and J.S. Fowler. 2000. Addiction, a dease of compulsion and drive: Involvement of the orbitofrontal cortex. Cerebral Cortex 10 (3): 318-325. https://doi. org/10.1093/cercor/10.3.318.

17. Fowler, J.S., N.D. Volkow, C.A. Kassed, and L. Chang. 2007. Imaging the addicted human brain. Science \& Practice Perspectives 3 (2): 4-16. https://doi.org/10.1151 /spp07324.

18. Schlaepfer, T.E., E. Lancaster, R. Heidbreder, E.C. Strain, M. Kosel, H.-U. Fisch, and G.D. Pearlson. 2006. Decreased frontal white-matter volume in chronic substance abuse. International Journal of Neuropsychopharmacology 9 (2): 147-153. https://doi.org/10.1017/s1461145705005705.

19. Volkow, N.D., J.S. Fowler, and G.-J. Wang. 2003. The addicted human brain: Insights from imaging studies. The Journal of Clinical Investigation 111 (10): 1444-1451. https://doi.org/10.1172/jci200318533.

20. Dennis, M., and C.K. Scott. 2007. Managing addiction as a chronic condition. Addiction Science \& Clinical Practice 4 (1): 45-55. https://doi.org/10.1151/ascp074145.

21. Brecher, E.M. 1972. Licit and illicit drugs. Boston: Little, Brown and Company.

22. McLellan, A.T., J.R. McKay, R. Forman, J. Cacciola, and J. Kemp. 2005. Reconsidering the evaluation of addiction treatment: From retrospective follow-up to concurrent recovery monitoring. Addiction 100 (4): 447-458. https://doi. org/10.1111/j.1360-0443.2005.01012.x.

23. Heyman, G.M. 2009a. Addiction in the first person. In Addiction: A disorder of choice, 44-64. Cambridge: Harvard University Press.

24. Heyman, G.M. 2009c. Once an addict, always an addict? In Addiction: A disorder of choice, 65-88. Cambridge: Harvard University Press.

25. Heyman, G.M. 2009d. Voluntary behavior, disease and addiction. In Addiction: A disorder of choice, 89-114. Cambridge: Harvard University Press.

26. Baumeister, R.F. 2017. Addiction, cigarette smoking, and voluntary control of action: Do cigarette smokers lose their free will? Addictive Behaviors Reports 5: 67-84. https://doi. org/10.1016/j.abrep.2017.01.003.

27. Charland, L.C. 2011. Decision-making capacity and responsibility in addiction. In Addiction and responsibility, ed. J. Poland and G. Graham. Cambridge: MIT Press. 
28. Buchanan, A. E. and D. W. Brock. 1989. Deciding for others: The ethics of surrogate decision making. Cambridge: Cambridge University Press.

29. Berg, J. W., P. S. Appelbaum, and T. Grisso. 1995. Constructing competence: formulating standards of legal competence to make medical decisions. Rutgers Law Review 48: 345-398.

30. Substance Abuse and Mental Health Services Administration. (2014). Results from the 2013 National Survey on drug use and health: Summary of national findings. NSDUH Series H-48. https://www.samhsa. gov/data/sites/default/files/NSDUHresults PDFWHTML2013/Web/NSDUHresults2013.pdf

31. Kessler, R.C., P. Berglund, O. Demler, R. Jin, K.R. Merikangas, and E.E. Walters. 2005a. Lifetime prevalence and age-of-onset distributions of dsm-iv disorders in the national comorbidity survey replication. Archives of General Psychiatry 62 (6): 593-602. https://doi. org/10.1001/archpsyc.62.6.593.

32. Kessler, R.C., W. Chiu, O. Demler, and E.E. Walters. 2005 b. Prevalence, severity, and comorbidity of 12-month dsm-iv disorders in the national comorbidity survey replication. Archives of General Psychiatry 62 (6): 617-627. https://doi.org/10.1001/archpsyc.62.6.617.

33. Anthony, J., and J. Helzer. 1991. Syndromes of drug abuse and dependence. In Psychiatric disorders in America: The epidemiologic catchment area study, ed. L. Robins and D. Regier, 116-154. New York: Free Press.

34. Sobell, L.C., T.P. Ellingstad, and M.B. Sobell. 2000. Natural recovery from alcohol and drug problems: Methodological review of the research with suggestions for future directions. Addiction 95 (5): 749-764. https://doi.org/10.1046/j.13600443.2000.95574911.x.

35. Russell, M., R.S. Peirce, A.W.K. Chan, W.F. Wieczorek, B.S. Moscato, and T.H. Nochajski. 2001. Natural recovery in a community-based sample of alcoholics: Study design and descriptive data. Substance Use and Misuse 36 (11): 1417-1441. https://doi.org/10.1081/JA-100106958.

36. Fenton, T., and R.W. Wiers. 2017. Free will, black qwans and addiction. Neuroethics 10 (1): 157-165. https://doi. org/10.1007/s12152-016-9290-7.

37. Kennett, J., N.A. Vincent, and A. Snoek. 2015. Drug addiction and criminal responsibility. In Handbook of neuroethics, ed. J. Clausen and N. Levy, 1065-1083. Dordrecht: Springer.

38. Charland, L.C. 2002. Cynthia's dilemma: Consenting to heroin prescription. The American Journal of Bioethics 2 (2): 37-47. https://doi.org/10.1162/152651602317533686.

39. Hyman, S.E. 2007. The neurobiology of addiction: Implications for voluntary control of behavior. American Journal of Bioethics 7 (1): 8-11. https://doi.org/10.1080 $/ 15265160601063969$.

40. Focquaert, F., A. Glenn, and A. Raine. 2015. Psychopathy and free will from a philosophical and cognitive neuroscience perspective. In Free will and the brain: Neuroscientific, philosophical, and legal perspectives, ed. W. Glannon, 103124. Cambridge: Cambridge University Press.
41. Morse, S.J. 2008. Determinism and the death of folk psychology: Two challenges to responsibility from neuroscience. Minnesota Journal of Law Science \& Technology 9 (1): $1-36$.

42. Argyriou, E., M. Um, C. Carron, and M.A. Cyders. 2017. Age and impulsive behavior in drug addiction: A review of past research and future directions. Pharmacology Biochemistry and Behavior 164: 106-117. https://doi. org/10.1016/j.pbb.2017.07.013.

43. Morse, S.J. 1985. Excusing the crazy: The insanity defense reconsidered. Southern California Law Review 58: 777.

44. Penney, S. 2012. Impulse control and criminal responsibility: Lessons from neuroscience. International Journal of Law and Psychiatry 35 (2): 99-103. https://doi.org/10.1016/j. ijlp.2011.12.004.

45. Schlosser, M.E. 2013. Conscious will, reason-responsiveness, and moral responsibility. The Journal of Ethics 17 (3): 205-232. https://doi.org/10.1007/s10892-013-9143-0.

46. Pickard, H. 2012. The purpose in chronic addiction. American Journal of Bioethics Neuroscience 3 (2): 40-49. https://doi.org/10.1080/21507740.2012.663058.

47. Charland, L.C. 2012. The varieties of compulsion in addiction. American Journal of Bioethics Neuroscience 3 (2): 50 51. https://doi.org/10.1080/21507740.2012.675011.

48. Morse, S.J. 2011. Addiction and criminal responsibility. In Addiction and responsibility, ed. J. Poland and G. Graham, 159-200. Cambridge: MIT Press.

49. Kennett, J. 2001. Agency and responsibility: A commonsense moral psychology. Oxford: Clarendon Press.

50. Kuhn, S., and J. Gallinat. 2011. Common biology of craving across legal and illegal drugs - a quantitative meta-analysis of cue-reactivity brain response. European Journal of Neuroscience 33 (7): 1318-1326. https://doi.org/10.1111 /j.1460-9568.2010.07590.x.

51. Panebianco, D., O. Gallupe, P.J. Carrington, and I. Colozzi. 2016. Personal support networks, social capital, and risk of relapse among individuals treated for substance use issues. International Journal of Drug Policy 27: 146-153. https://doi.org/10.1016/j.drugpo.2015.09.009.

52. Baler, R.D., and N.D. Volkow. 2006. Drug addiction: The neurobiology of disrupted self-control. Trends in Molecular Medicine 12 (12): 559-566. https://doi.org/10.1016/j. molmed.2006.10.005.

53. Snoek, A. 2017. How to recover from a brain disease: Is addiction a disease, or is there a disease-like stage in addiction? Neuroethics 10 (1): 185-194. https://doi.org/10.1007 /s12152-017-9312-0.

54. Reith, G. 1999. In search of lost time: Recall, projection and the phenomenology of addiction. Time \& Society 8 (1): 99117. https://doi.org/10.1177/0961463x99008001005.

55. Shinebourne, P., and J.A. Smith. 2010. The communicative power of metaphors: An analysis and interpretation of metaphors in accounts of the experience of addiction. Psychology and Psychotherapy: Theory, Research and Practice 83 (1): 59-73. https://doi.org/10.1348/147608309 x468077.

56. Moffitt, T.E. 1993. Adolescence-limited and life-coursepersistent antisocial behavior: A developmental taxonomy. 
Psychological Review 100 (4): 674-701. https://doi. org/10.4324/9781315085081-25.

57. Marlatt, G.A. 1996. Taxonomy of high-risk situations for alcohol relapse: Evolution and development of a cognitivebehavioral model. Addiction 91 (12s1): 37-50. https://doi. org/10.1111/j.1360-0443.1996.tb02326.x.

58. Levy, N. 2013. Addiction is not a brain disease (and it matters). Frontiers of Psychiatry 4: 24. https://doi. org/10.3389/fpsyt.2013.00024.

59. Macilwaine, S. 1900. What is a disease? British Medical Journal 2 (2085): 1703-1704. https://doi.org/10.1136 /bmj.2.2085.1703.

60. Kendell, R.E. 1975. The concept of disease and its implications for psychiatry. The British Journal of Psychiatry 127 (4): 305-315. https://doi.org/10.1192/bjp.127.4.305.

61. Satel, S.L., and S.O. Lilienfeld. 2017. If addiction is not best conceptualized a brain disease, then what kind of disease is it? Neuroethics 10 (1): 19-24. https://doi.org/10.1007 /s12152-016-9287-2.

62. Scully, J.L. 2004. What is a disease? EMBO Reports 5 (7): 650-653. https://doi.org/10.1038/sj.embor.7400195.

63. Cooper, J. 2004. Disorders are different from diseases. World psychiatry: official journal of the World Psychiatric Association (WPA) 3 (1): 24-24.
64. Wakefield, J.C. 1992. The concept of mental disorder: On the boundary between biological facts and social values. American Psychologist 47 (3): 373-388. https://doi. org/10.1037//0003-066x.47.3.373.

65. Morse, S.J. 2017. Addiction, choice and criminal law. In Addiction and choice: Rethinking the relationship, ed. N. Heather and G. Segal, 426-448. Oxford: Oxford University Press.

66. Beukers, M. 2017. Over de grenzen van de stoornis ("The mental disorder in criminal law"). ( $\mathrm{PhD} \mathrm{PhD}$ thesis), Erasmus University Rotterdam.

67. Vincent, N.A. 2008. Responsibility, dysfunction and capacity. Neuroethics 1 (3): 199-204. https://doi.org/10.1007 /s12152-008-9022-8.

68. Meynen, G. 2016. Legal insanity: Explorations in psychiatry, law, and ethics. Vol. 71. Basel: Springer.

Publisher's Note Springer Nature remains neutral with regard to jurisdictional claims in published maps and institutional affiliations. 